\title{
The global warming debate
}

\author{
WANG ShaoWu \\ Department of Atmospheric Science, School of Physics, Peking University, Beijing 100871, China
}

Received April 23, 2010; accepted May 12, 2010

Nowadays, global warming and the anthropogenic impact on the climate is one of the hottest topics of scientific research and world media interest. Concerns about this issue culminated with the Copenhagen Conference on December 7-18, 2009. The Intergovernmental Panel on Climate Change (IPCC) published their Fourth Assessment Report (IPCCAR4) [1] in 2007, in which it is concluded that most of the observed increase in the global average temperature since the mid-20th century is very likely due to the observed increase in anthropogenic greenhouse gas concentrations. In addition, "Climate Change Science Compendium" [2] and "Copenhagen Diagnosis" [3] were published before the conference. On the other hand, the Nongovernmental International Panel on Climate Change (NIPCC) was established in 2007 by a group of scientists who wanted to break the monopoly and one-sidedness of the scientific debate over climate change by the IPCC. A summary for policy-makers written by the NIPCC [4] was issued in April 2008, and a full report [5] was issued in June 2009, which declared that nature, not human activity, rules the climate. Recently, there has been a series of "Climate Gates", "Glacial Gates", and "Amazon Rainforest Gates" [6] that damaged the reputation of the IPCC [7], which was considered an authoritative institution in the field of climate change. The prestige of the IPCC has recovered to some extent [8], following clarification of the Climate Gate episodes. However, there is still a level of debate about whether global warming is caused mainly by anthropogenic activity. There have been an increasing number of papers published around the world contributing to the issue. Therefore, it is impossible to draw conclusions based on a few limited papers, and the proper way to pursue the topic is to join the discussion and debate.

The NIPCC has recently retreated from its former position, and even Singer has suspected climate warming to be real $[9,10]$. Now that the key question in the debate has moved to whether climate warming is caused by natural factors or an anthropogenic impact, global warming has been accepted as fact. In any event, uncertainties remain in reconstructing the global mean temperature series, from

email: swwang@pku.edu.cn which global warming has been identified. There are three series, namely HadCRUT3 [11], GISS [12], and NCDC [13]. The first has come under suspicion in Climate Gate episodes. However, the HadCRUT3 series shows the lowest warming trend over the last 30 years among the three series, which contradicts criticism that the Climate Research Unit at the University of East Anglia (CRU) were hiding data and falsifying scientific evidence on global warming. On the other band, the three series give nearly the same warming trend over the last 30 years of the 20th century, with the basis of the later two series including satellite data.

However, there are two important uncertainties in the temperature series: incompleteness of the geographical coverage of data and the heat island effect. Temperature records are available only for $15 \%$ to $20 \%$ of grid points for the mid- to late 19th century, and data coverage reduced significantly in the periods of the two World Wars; thus, the series have great inhomogeneity. Therefore, none of the available global mean temperature series can be regarded as satisfactory. The impact of incompleteness of the data coverage in estimation of the warming trend is to be studied. In China, the incompleteness of data coverage still hampers the reconstruction of a better temperature series. Temperature observations are available only from a few stations along the coast for the late 19th century. The number of stations recording temperature observations increased to hundreds in the early 1950s, but no temperature observations are available in western China for the 1940s and earlier. There is great uncertainty in the reconstruction of the temperature series in China for the whole 20th century and earlier owing to the incompleteness of data coverage.

Uncertainty in reconstruction of the temperature series also relates to the heat island effect. The expansion of a city makes the proper conditions of a standard meteorological platform improper. It is unknown how many stations are affected by the heat island effect and to what extent, although the CRU has claimed that data strongly influenced by the heat island effect have been eliminated. Chinese scientists have considered the uncertainty due to the heat island effect and other factors [14-16].

Another issue in the debate is the attribution of global 
warming. The IPCC has concentrated on the anthropogenic impact since its establishment in 1990. Natural factors were not taken into consideration in projecting the temperature change in the next 50 or 100 years. Of course, the natural variability in temperature is difficult to project. For example, at the present time, there is no available method of predicting volcanism or thermohaline circulation over the next few decades. Variations in the solar constant are limited to within about $0.1 \%$ [17] and are not large enough to result in significant climate change according to the climate models. Changes in the interdecadal variability of the solar constant are to be understood. Research on the theory and mechanism of the effects of cosmic rays on the Earth's climate is in the early stage of development $[18,19]$; therefore, there is no practicable prediction method of natural variability. A group of scientists has attempted to make the prediction considering periodicity, such as 65,80 , or 120 a, in solar activity [20]. It was predicted in the late 20th century that a cold period would occur in the 2020s or 2030s. Recently, there have been more indications that a cold period will occur in the next few decades, considering the long-term change in solar activity [21-23]. Indeed, temperature change in the 20th century was ruled not only by enhancement of the greenhouse effect; the cold period from the 1950 s to 1970 s is difficult to attribute to anthropogenic influence because the concentration of $\mathrm{CO}_{2}$ in the atmosphere increased significantly after World War II. Similarly, global warming has paused in the recent decade of 1999-2008 according to HadCRUT3 [24,25]; however, the concentration of $\mathrm{CO}_{2}$ in the atmosphere during this decade increased as usual. This indicates that the temperature change does not tightly follow variations in the $\mathrm{CO}_{2}$ concentration. The warming in the 1940s also shows the important role of natural factors in controlling temperature change. There is no peak of $\mathrm{CO}_{2}$ concentration in the 1940 s, so the warming is sometimes attributed to a quiet period of volcanism. This is in accordance with results obtained by Chinese scientists [26], who found that the 1940s warming in China was mainly not observed in winter, in terms of daily minimum temperature, or at higher latitudes, which is contrary to the theory of the anthropogenic effect. Another example that shows the importance of natural factors in controlling temperature changes is the occurrence of cold events in the warming period; e.g., those in the first decade of the 21 st century in China while the temperature increased as usual. The snow storms in the south in January 2008, the cool summer in the northeast in June 2009, and snow storms in the north during the 2009-2010 winter remind us that there is still a natural variability in climate change. The natural impact cannot be denied, although global warming will continue to some extent in the future.

In conclusion, fully attributing climate change to the anthropogenic effect is a one-sided view, but fully denying the human impact on the climate is also improper. More attention from scientific researchers, the public, and the media is needed to promote further development of the science of climate change.

1 Solomon S, Qin D, Manning M, et al. Climate Change 2007: The Physical Science Basis, Contribution of Working Group I to the Fourth Assessment Report of the Intergovernmental Panel on Climate Change. Cambridge and New York: Cambridge University Press, 2007. 996

2 Bálint M, Jabbour J, McMullen C, et al. Climate Change Science Compendium 2009. SCOPE, WMO: 2009. 68

3 Allison I, Bindoff N L, Binaschadler, et al. The Copenhagen Diagnosis. Sydney, Australia: The University of New South Wales Climate Change Research Centre (CCRC), 2009. 60

4 Singer S F, Anderson W, Goldberg F, et al. Nature, not human activity, rules the climate: Summary for policymakers of the report of the Nongovernmental International Panel on Climate Change (NIPCC). Chicago, IL: The Heatland Institute, 2008. 40

5 Idso C, Singer S F. Climate Change Reconsidered: 2009 Report of the Nongovernmental International Panel on Climate Change (NIPCC). The Heartland Institute, 2009. 868

6 Heffernan O. Climate data spat intensifies. Nature, 2009, 460: 787

7 Schiermeier Q. IPCC flooded by criticism. Nature, 2010, 463: 596-597

8 Tollefson J. World looks ahead post-Copenhagen. Nature, 2009, 462: 966-967

9 Singer S F. Human contribution on climate change questionable. Eos, 1999, 80: 183

10 Singer S F. Science editor bias on climate change? Science, 2003, 301: 595-596

11 Brohan P, Kennedy J J, Harris I, et al. Uncertainty estimates in regional and global observed temperature changes: A new data set from 1850. J Geophys Res, 2006, 111: D12106, doi:10.1029/2005JD006548

12 Hansen J, Ruedy R, Sato M, et al. A closer look at United States and global surface temperature change. J Geophys Res, 2001, 106: 2394723963

13 Smith T M, Reynolas R W. A global merged land-air-sea surface temperature reconstruction based on historical observations (18801997). J Clim, 2005, 18: 2021-2036

14 Ren G Y, Chu Z Y, Zhou J X, et al. Urbanization effects on observed surface air temperature in North China. J Clim, 2008, 21: 1333-1348

15 Li Q X, Dong W J. Detection and adjustment of undocumented discontinuities in Chinese temperature series using a composite approach. Adv Atmos Sci, 2009, 26:143-153

16 Zhao Z C, Wang S W, Luo Y, et al. Uncertainty analysis of climate warming during the last 100 years. Sci Technol Rev, 2009, 27: 41-48

17 Houghton J T, Ding Y, Griggs D J, et al. Climate Change 2001: the Scientific Basis Contribution of Working Group 1 to Third Assessment Report of the Intergovernmental Panel on Climate Change. Cambridge, United Kingdom and New York: Cambridge University Press, 2001. 881

18 Wang Y M, Lean J L, Sheeley N R. Modeling the sun's magnetic field and irradiance since 1713. Astrophys J, 2005, 625: 522-538

19 Svensmark H. Cosmoclimatology: A new theory emerges. Astron Geophys, 2007, 48: 18-24

20 Schlesinger M E, Ramankutty N. An oscillation in global climate system of period 65-70 years. Nature, 1994, 367: 723-726

21 Abreu J A, Beer J, Steinhilber, et al. For how long will the current grand maximum of solar activity persist. Geophys Res Lett, 2008, 35: L20109

22 Lvingston W, Penn M. Are sunspots different during this solar minimum? Eos, 2009, 90: 257-264

23 Lockwood M. Solar change and climate: An update in the light of the current exceptional solar minimum. Proc R Soc A, 2010, 466: 303-329

24 Knight J, Kennedy J J, Folland C, et al. Do global temperature trends over the last decade falsify climate predictions? In State of the Climate in 2008. Bull Amer Meteor Soc, 2009, 90: S22-23

25 Kerr R A. What happened to global warming? Scientists say just wait a bit. Science, 2009, 326: 28-29

26 Zhao Z C, Ding Y H, Luo Y, et al. Recent studies on attributions of climate change in China. Acta Meteorol Sin, 2005, 19: 389-400 